Purdue University

Purdue e-Pubs

2019

\title{
A Longitudinal Examination of the Impact of Major Life Events on Physical Activity
}

Elizabeth Richards

Patricia A. Thomas

Anna K. Forster

Zachary Hass

Follow this and additional works at: https://docs.lib.purdue.edu/nursingpubs

This document has been made available through Purdue e-Pubs, a service of the Purdue University Libraries.

Please contact epubs@purdue.edu for additional information. 
A Longitudinal Examination of the Impact of Major Life Events on Physical Activity 


\begin{abstract}
Background: Despite promotion of physical activity guidelines, less than one third of U.S. adults are sufficiently active and an even larger number of older adults fail to meet guidelines. To address this major public health issue, it is essential to broadly consider determinants of physical activity. Aims: This study explores how physical activity behavior is impacted by the experience of major life events and considers the stress experienced due to these events across the life course. Methods: Nationally representative panel data from the American’s Changing Lives survey (1986-2012) was used to analyze a growth model with age-based trajectories to examine the relationship between major life events and physical activity overall and separately by gender and race. Results: In the overall sample, retiring was associated with greater physical activity at baseline. As respondents aged, entering into retirement was associated with decreased physical activity, while a parent or friend dying were associated with greater physical activity. Differences by gender and race were also seen over time. Conclusions: Results show that when considering physical activity trajectories, experiencing these major life events is not always detrimental, and in some cases may be beneficial. Considering these impacts is important in planning effective health promotion interventions to increase and promote maintenance of physical activity, while paying attention to specific differences by gender and race.
\end{abstract}

Keywords: exercise; stress; health behavior 


\section{Introduction}

The importance of physical activity (PA) for a healthy lifestyle is well established (U.S. Department of Health and Human Services, 2008). Regular PA prevents or delays the onset of chronic diseases such as coronary heart disease, stroke, diabetes, depression, and cancer (Kämpfen \& Maurer, 2016). Even though the benefits of PA are well-known, physical inactivity remains a major public health concern (Office of Disease Prevention and Health Promotion, 2017). United States PA guidelines recommend regular, moderate to vigorous intensity PA for all adults, regardless of age (U.S. Department of Health and Human Services, 2008). Despite promotion of these guidelines, the same source indicates that less than one third of U.S. adults are considered sufficiently active. An even larger number of older adults fail to meet recommended activity guidelines and PA prevalence rates steadily decline with age (ChodzkoZajko et al., 2009). Furthermore, women are consistently less active than men and whites are consistently more active than other races (Centers for Disease Control and Prevention, 2014). Importantly, these disparities in PA behavior further increase with age (Centers for Disease Control and Prevention, 2014).

There are several well-known determinants of PA which are often categorized as intrapersonal, interpersonal, and environmental determinants (Bauman et al., 2012). Intrapersonal determinants such as age, health status, self-efficacy, personal beliefs about PA, and intention to exercise have all been shown to be direct correlates of PA. Interpersonal determinants of PA include social support and cultural norms and practices. Environmental factors such as neighborhood walkability, aesthetics, perceptions of safety and proximity to recreation facilities are also consistent determinants of PA. 
Life events such as change in employment status, residence, physical health status, relationship status, and family structure are considered eventful stressors and the stress experienced from these life events likely impacts health behaviors including PA on the intrapersonal level (Pearlin \& Skaff, 1996; Stetson, Rahn, Dubbert, Wilner, \& Mercury, 1997). Compounding the decline in PA seen with aging, greater perceived stress is also associated with decreased PA among adults (Ng \& Jeffery, 2003). Therefore, the experience of major life events as individuals' age may be particularly important because the response to these events may exacerbate already declining PA levels seen in older adults.

\section{Major Life Events and Physical Activity}

A systematic review of 19 studies identified decreased PA in women who began paid work, started a live-in relationship, transitioned to a university, became married, or became first time parents (Allender, Hutchinson, \& Foster, 2008). While non-significant, it is worth noting that in this review, men were found to have decreased PA after divorce. However, most of these reviewed studies were cross-sectional in design with limited sample sizes (e.g., Bray \& Born, 2010; Butler, Black, Blue, \& Greteback, 2004), limiting the ability to infer causality or generalization to larger populations.

More recently, a review of 34 studies examining the impact of life events on PA discovered mixed findings regarding PA among men and women, and within age groups (Engberg et al., 2012). For example, transitioning to a university, having a child, remarrying, or experiencing multiple simultaneous life events was associated with decreased PA in both men and women (Engberg et al., 2012). This same source indicated that in younger women, beginning work, changing work conditions, cohabitating, getting married, becoming pregnant, and becoming divorced or separated was also associated with a decrease in PA. Middle-aged women 
saw an increase in PA when work conditions changed or their income decreased (Engberg et al., 2012). Similar findings were not seen among men. Notable limitations of this review were the inclusion of studies with smaller sample sizes and the recognized potential of non-response bias.

A body of research has focused on the major life events of retirement and widowhood. Although retirement has been linked to changes in PA, there are conflicting study results regarding the direction of this relationship. Using cross-sectional data, Allender, Foster, and Boxer (2008) found a decrease in PA around retirement in men ages 65 to 74, but no significant change in the PA of women. These men were found to be $23 \%$ less likely to meet PA guidelines than men ages 55 to 64 . A longitudinal study by Kämpfen \& Maurer (2016) concluded that retirement was associated with a significant increased likelihood of meeting PA guidelines in both men and women overall but showed a significant decreased likelihood of meeting PA guidelines specifically among black respondents. Furthermore, when looking at PA trajectories before and after retirement, Feng and colleagues (2016) found that men and women entering into semi- or full retirement were more likely to increase their PA.

Furthermore, gender differences have been reported in PA behavior after the death of a spouse. Widowers have been found to be more physically active immediately after the death of their spouse, but over time this increase was not sustained and eventually PA decreased (Stahl \& Schulz, 2014). This is possibly due to stress coping immediately after the loss and then eventual resolution of the stressor. In contrast, women have been found to walk for shorter periods of time during the first year after the death of a spouse but then increase walking behaviors one to five years later (Grimby, Johansson, Sundh, \& Grimby, 2008). This indicates long-term widowhood may also be associated with increased PA in women (Engberg et al., 2012). 
Understanding the effects of these life events on the PA trajectories of older adults is critical as significant declines in activity during periods of these life events could place individuals at increased risk for compromised health. However, the reverse could be true as increasing PA in light of these life events could combat detrimental health effects often experienced in tandem with these life events. For example, in a study of Taiwanese women, widows who were sufficiently active increased their life expectancy by four years and reduced their risk of depression compared to inactive widows (Li et al., 2016).

\section{Gender, Race, and Stress Responses to PA}

Additionally, it is important to consider how gender and racial groups may experience major life events differently, with implications for their physical activity patterns. Race and gender have been consistently identified to impact the experience of stress (Bey, Waring, Jesdale, \& Person, 2018; Ng \& Jeffery, 2003; Rosenfield \& Mouzon, 2013) For instance, different stress responses have been seen between men and women for numerous health conditions and behaviors. For example, after the loss of a spouse men are more likely to become ill or die than women (Baum \& Grunberg, 1991). Men also tend to experience greater increases in blood pressure when stressed, while women show an increase in heart rate (Baum \& Grunberg, 1991).

Women experiencing stress are more likely to show signs of depression, utilize social networks for support, and display obsessive-compulsive behaviors compared to men (Baum \& Grunberg, 1991). Furthermore, a woman's stress response of depression has been shown to lead to lower levels of PA (Rosenfield \& Mouzon, 2013). Men, on the other hand, are more likely to abuse substances, commit suicide, and find support from a singular individual instead of a network (Baum \& Grunberg, 1991). These different gender responses to stress can also influence 
health behaviors including PA. For example, men are more likely to externalize stress, and participating in vigorous PA is one avenue to do so (Rosenfield \& Mouzon, 2013).

In a review of 168 studies, Stults-Kolehmainen and Sinha (2013) found conflicting results regarding whether PA increases or decreases in response to stress. Approximately $73 \%$ of the reviewed studies demonstrated that stress was associated with less PA, while $17 \%$ of the reviewed studies showed an increase in PA in the presence of stress. While an inverse relationship between stress and PA has been found for both men and women (Ng \& Jeffery, 2003; Stetson et al., 1997; Stults-Kolehmainen \& Sinha, 2013), the strength of the relationship has varied across studies, sometimes showing that men were more vulnerable than women, while other studies observed the opposite trend (Stults-Kolehmainen \& Sinha, 2013). These mixed results could be due to different motivations to exercise and current stage of change (StultsKolehmainen \& Sinha, 2013).

Furthermore, race has been shown to affect the stress (Bey et al., 2018). Studies have shown that black individuals are more likely to display somatic (e.g., headaches, insomnia) rather than affective (e.g., anxiety, depression) responses to stress (Bey et al., 2018). In addition, when faced with stress, blacks may have less availability of support systems, compared to whites, which can lead to unhealthy coping such as risky health behaviors including decreased physical activity (Jackson, Knight, \& Rafferty, 2010). However, recent research suggests that black and Hispanic Americans may be less upset by some domains of stressors compared to whites (Brown, Mitchell, \& Ailshire, 2018), and these differences in stress appraisals may have consequences for health and health behaviors.

In a study specifically examining the impact of job-related stress on PA, Bennett and colleagues (2006) found significant differences among whites and racial minorities. Whites who 
reported experiencing job strain had close to 60 minutes of weekly leisure PA less than whites who did not experience job strain. Inversely, racial minorities reporting job-related stress accumulated more weekly leisure PA than their counterparts not reporting job stress. Interestingly, significant differences were not identified between specific racial minorities (e.g., between blacks and Asians).

In sum, an individual's stress response is generally associated with decreased levels of PA (Kaplan, Newsom, McFarland, \& Lu, 2011; Umberson, Liu, \& Reczek, 2008). However, PA may also be a means of coping for some individuals during times of stress (Rosenfield \& Mouzon, 2013; Salmon, 2001). These varying responses to stress between men and women and between different races further validate the importance in examining the effect of life events on PA separately for these subpopulations.

Further, prior studies do not allow clear conclusions to be drawn regarding the impact of major life events on PA. Previous studies have been limited by cross-sectional design (e.g., Bauman et al., 2012; Bray \& Born, 2004), examining only one gender (e.g., Stetson et al., 1997), or have presented mixed findings (Allender, Foster, \& Boxer, 2008; Feng et al., 2016).

Additional study limitations include small sample sizes (Bray \& Born, 2004; Butler et al., 2004) and non-representative samples (Grimby et al., 2008; Li et al., 2016). These limitations point to the need for further research that includes the use of a longitudinal design with a nationally representative sample.

In order to better promote PA, there needs to be continued research in how life events impact PA throughout the life course. As the United States’ population ages, more and more older adults are at risk for an inactive lifestyle. Knowing how life events impact older adults, including specific differences by gender and race, will aid in better promotion of regular PA 
among this population. Given the relatively low prevalence rates of PA participation in spite of the recognized health benefits of being physically active, it is essential to consider determinants of PA widely. The specific impact of intrapersonal factors of major life events on PA is not well understood. The present study draws from a stress and life course framework (Pearlin \& Skaff, 1996) to address the following research questions: 1) How is PA impacted by the experience of major life events? 2) How does the relationship between these life events and PA change with age? 3) How does the relationship between these life events and PA differ for men and women? 4) How does the relationship between these life events and PA differ by race?

\section{Methods}

\section{Sample}

Data was obtained from the American's Changing Lives (ACL) survey, a nationally representative, longitudinal panel study. Five waves of data were collected in 1986, 1989, 1994, 2001/2002, and 2011/2012 (House, 2014). Wave $1(\mathrm{~N}=3,617)$ included probability sampling of those 25 years and older, with an oversampling of black respondents and individuals aged 60 and older. There was a 68-83\% response rate over the course of the study, depending on the wave. The analytic sample consisted of 11,822 person-age observations embedded within 3,617 individuals measured between one and five times. Data were transformed such that observations were matched to the age of the individual at the time of the survey rather than the survey year.

\section{Measures}

Physical activity. Three questions were included in the PA measure: 1) frequency of active sports or exercise; 2) frequency of taking walks; and 3) frequency working in the garden or yard. Each question had four possible response options: often, sometimes, rarely, and never, with higher values indicating more frequent PA. This three item PA measure has been frequently 
used in past research (e.g., Infurna, Ram, \& Gerstorf, 2013; Musick \& Wilson, 2003; Shaw, Liang, Krause, Gallant, \& McGeever, 2010). However, to account for measurement error, an ordered categorical confirmatory factor analysis model (or item response theory analysis model) utilizing sampling weights was fit to estimate a single continuous latent variable for PA (Bollen, 1989). The model was fit to wave 1 data and factor scores were estimated from this model for all waves, using Mplus version 7.

Life events. Life events were categorized into five groups: 1) change in marital status; 2) change in employment status; 3) death of a loved one; 4) change in residence; and 5) becoming a caregiver. Change in marital status included two variables: becoming married or becoming divorced within the past three years. Change in employment status included two variables: becoming retired or involuntarily losing a job within the past three years. Death of a loved one included four variables: death of a child, death of a parent, death of a spouse, or death of a close friend within the past three years. Change in residence was assessed with one variable asking if a participant had moved to a new residence within the past three years. Becoming a caregiver was assessed with one variable asking if the participant currently provides or arranges care for an impaired person. Additionally the sum of life events was calculated for each respondent at each wave.

Covariates. Assessment of demographic information included age, sex, race (white vs. non-white), highest level of education (13+ education years), and annual household income (> $\$ 25,000)$. In addition, body mass index, functional health, the number of chronic conditions (010), and the proportion of waves of data collection respondents participated in were controlled. Body mass index (BMI) was calculated based on self-reported height and weight. Functional impairment was measured with the four-level Functional Health Index (FHI) $(0=$ the most 
functional impairment, 3=no functional impairment. BMI, FHI, and chronic conditions were calculated for each wave where data were available. Age was updated for each wave, but all other demographic information was taken from wave 1.

\section{Data Analysis}

Given this study's emphasis on the life course perspective and evidence that PA declines with age (Bauman et al., 2012), age rather than wave of survey was used as the metric of time in the models. This is an estimation strategy especially well-suited to the life course framework and advantageous in allowing data that are unbalanced in time (Yang \& Lee, 2009). Therefore, a growth model with age-based trajectories was used to test the relationship between PA and life events. Data were transformed such that each observation was at a particular age clustered within a respondent. Age was centered on 60 to give a more meaningful intercept. A linear growth model was estimated for each respondent with a random intercept and slope. The random effects account for correlation within an individual. Interactions were included between all life events and age. A supplementary model was fit with the count of life events in place of the specific events to examine the cumulative effect. Additional models were fit conditional on gender and race. All models were fit using restricted maximum likelihood in Proc Mixed, SAS version 9.4 and utilized sampling weights.

\section{Results}

Table 1 displays descriptive statistics overall and by gender. The sample was predominantly white females with an average age of $54 \pm 17.6$ years. On average, men had significantly higher incomes and education level than women. Fifty-five percent of the overall sample was currently married, however a higher percent of men were married (65\%) and a higher percent of women were widowed (24\%). When asked to rate their functional health (FHI), 
the majority of the sample rated themselves as not impaired (77\%). In addition, the average BMI was $26.0 \pm 5.1 \mathrm{~kg} / \mathrm{m}^{2}$ and the average number of chronic conditions was 1.40 per participant.

Table 2 displays age-based trajectories of PA for the full sample and separately for men and women and for white and non-white respondents. Among the full sample, retiring ( $p=0.0114)$ was associated with greater PA at baseline. As the sample aged, a parent $(p=0.0418)$ or friend ( $p=0.0154)$ dying were associated with greater PA. On the other hand, as the sample aged, entering into retirement $(p=0.0114)$ was associated with decreased PA. In a supplementary analysis, a model using a count variable for life events indicated a positive relationship between the number of life events and physical activity $(p=0.0007)$.

Specifically among women, experiencing the death of a parent $(p=0.0499)$ and retiring was associated with greater PA at baseline $(p=0.0004)$. However, entering into retirement was associated with less PA as women aged $(p=0.0023)$. In addition, experiencing the death of a parent ( $p=0.0206)$ or changing residence $(p=0.0217)$ were also associated with greater PA as women aged. Specifically among men, becoming a caregiver was associated with greater PA at baseline ( $p=0.0233$ ) while experiencing the death of a close friend was associated with more PA as men aged $(p=0.0103)$.

Specifically among non-white participants, experiencing the death of a child was associated with greater PA at baseline $(p=0.0319)$. However, experiencing the loss of a job was associated with less PA as this sub-sample aged ( $p=0.0413)$. Specifically among white participants, retirement $(p=0.0002)$ was associated with greater PA at baseline. As white participants aged, experiencing the death of a friend was associated with increased PA $(p=0.0204)$ while retiring was associated with less PA as this sub-sample aged $(p=0.0022)$.

\section{Discussion}


By answering each of the research questions, the findings from this study help to advance understanding of the impact of major life events on physical activity (PA) behavior in American adults overall and specifically in gender and race subsamples. Alarmingly, PA prevalence declines with age, making older adults increasingly vulnerable to the harmful health effects of inactivity. As the aging population continues to grow, it is imperative researchers continue to explore important factors in PA behavior. Major life events that individuals experience across the life course may be key factors influencing PA behaviors and it is very possible that these life events may become increasingly relevant as people age. Guided by a review of literature and conceptual framework of gender and race differences in stress response across the life course, longitudinal, nationally representative panel data from the Americans' Changing Lives survey was analyzed to examine how major life events are associated with PA as individuals’ age.

To answer the first research question, how is PA influenced by the experience of major life events, it was that found that retirement was associated with increased PA at baseline in the full sample. Overall, none of the life events were associated with decreased PA at baseline in the full sample. The second research question examined how the relationship between major life events and PA changes with age. Findings suggest that as the sample aged, retirement was associated with a decrease in PA. However, other major life events such as death of a parent or friend were associated with increased PA as the sample aged.

Next, this study sought to examine how the relationships between these life events and PA differed for men and women. Results suggest that men's PA was significantly influenced by becoming a caregiver and experiencing the death of a close friend, while women's PA was significantly impacted by the death of a parent, moving, or entering into retirement. These differences could be partly due to men having an adjustment period of their health habits in 
response to the health events of people within their social network. Differences could also be attributed to men's and women's differing use of social networks. Men tend to rely on only one other individual for support, while women rely on a network of people for support (Baum \& Grunberg, 1991). This may explain why women are affected by events involving a larger social group, such as moving or retiring, while men are affected by events revolving around one person such as becoming a caregiver or the death of a close friend.

Lastly, how relationships between these life events and PA differed by race was examined. Findings support that non-white participants' PA was affected by the death of a child or the loss of a job. The PA of white participants was significantly impacted by retirement or the death of a friend. These differences seen between races could be related to the coping strategies predominantly used and the availability of support systems that can vary by race (Jackson et al, 2010).

As previously stated, past studies have presented conflicting results on the impact of retirement on PA (Allender, Foster, \& Boxer, 2008; Engberg et al., 2012). This longitudinal analysis shows that retirement is related to increased PA at baseline but that as people age, retirement is associated with less PA. Moreover, this pattern is pronounced among women, but not men, in the gender-stratified analyses and in white participants, but not non-white participants, in the race-stratified analyses. Findings are in line with findings from Feng and colleagues (2016) which demonstrated that women entering semi- or full retirement had increases in PA. It is likely that the longitudinal approach used in this study is able to capture more of the nuances within the retirement-PA relationship.

\section{Limitations}


Limitations of this study should be considered within the context of study findings. First, this study relied on self-reported PA, which is prone to social desirability and recall bias. Furthermore, the wording of the questions may have limited the assessment of PA. For example, one of the PA questions assessed the frequency of gardening or working in the yard. This item may be more meaningful to older adults or to respondents in more suburban or rural settings. In addition, it is possible that these major life events may have overlapped in time, making it difficult to determine the effects of one specific life event on PA. Although these limitations raise issues to be addressed in future research, findings from the current study advance the understanding of how major life events impact PA. Importantly, this is one of the first studies to utilize a long-term, longitudinal cohort design to assess the impact of several major life events on PA.

\section{Conclusion}

This study provides further insight into the impact of major life events on PA behavior from a life course perspective stratified by gender and race. This life course perspective is vital as stress and health behaviors are not constant over the life course. In fact, it is widely known that PA declines as people age. These changes in PA could be due to secondary aging effects such as chronic disease or functional limitations; however, findings from this study suggest that several major life events had positive effects on PA as people age. Importantly, these findings remained significant even after adjusting for functional limitations and chronic conditions which are known predictors of PA and socioeconomic status, a known predictor of stress frequency. The impact of these life events could result in a slower decline in PA, which could combat negative effects associated with aging. 
Furthermore, findings from the current study suggest that major life events do affect PA differently among subsamples of gender and race. Examining the impact of major life events on PA separately for these subsamples provides important insights into how and why PA may increase or decrease across age. Results show that when specifically considering PA, experiencing these major life events is not always detrimental, and in some cases may be beneficial. Considering these impacts is important in planning effective health promotion interventions focused on key life points to increase and promote maintenance of PA. Further, addressing specific subsamples of the population separately may prove to be beneficial in successfully increasing adherence to PA guidelines as people age. 


\section{References}

Allender, S., Foster, C., \& Boxer, A. (2008). Occupational and non-occupational physical activity and the social determinants of physical activity: Results from the Health Survey for England. Journal of Physical Activity and Health, 5(1), 104-116.

Allender, S., Hutchinson, L., \& Foster, C. (2008). Life-change events and participation in physical activity: A systematic review. Health Promotion International, 23(2), 160-172.

Baum, A., \& Grunberg, N. (1991). Gender, stress, and health. Health Psychology, 10(2), 80-85.

Bauman, A., Reis, R., Sallis, J., Wells, C., Loos, R., \& Martin, B. (2012). Correlates of physical activity: Why are some people physically active and others not? The Lancet, 380(9838), 258-271.

Bennett, G., Wolin, K., Avrunin, J., Stoddard, A., Sorensen, G., Barbeau, E., \& Emmons, K. (2006). Does race/ethnicity moderate the association between job strain and leisure time physical activity? Annals of Behavioral Medicine, 32(1), 60-67.

Bey, G., Waring, M., Jesdale, B., \& Person, S. (2018). Gendered race modification of the association between chronic stress and depression among black and white U.S. adults. American Journal of Orthopsychiatry, 88(2), 151-160.

Bollen, K. (1989). Structural Equation Modeling with Latent Variables. New York: Wiley.

Bray S. \& Born H. (2004). Transition to university and vigorous physical activity: Implications for health and psychological well-being. Journal of American College Health, 52(2), 181188.

Brown, L., Mitchell, U.A., \& Ailshire, J. (2018). Disentangling the stress process: Race/Ethnic differences in the exposure and appraisal of chronic stressors among older adults. The Journals of Gerontology: Series B. Advance online publication. 
Butler, S., Black, D., Blue, C., \& Greteback, R. (2004). Change in diet, physical activity, and body weight in female college freshman. American Journal of Health Behavior, 28(1), 24-32.

Centers for Disease Control and Prevention. (2014). Facts about physical activity. Retrieved from https://www.cdc.gov/physicalactivity/data/facts.htm

Chodzko-Zajko, W., Proctor, N., Singh, M., Minson, C., Nigg, C., Salem, G., \& Skinner, J. (2009). Exercise and physical activity for older adults. Medicine \& Science in Sports \& Exercise, doi: 10.1249/MSS.0b013e3181a0c95c

Engberg, E., Alen, M., Kukkonen-Harjula, K., Peltonen, J., Tikkanen H., \& Pekkarinen H. (2012). Life events and change in leisure time physical activity: A systematic review. Sports Medicine, 42(5), 433-447.

Feng, X., Croteau, K., Kolt, G., \& Astell-Burt, T. (2016). Does retirement mean more physical activity? A longitudinal study. BioMed Central Public Health, 16.

Grimby, A., Johansson, A., Sundh, V., \& Grimby, G. (2008). Walking habits in elderly widows. American Journal of Hospice \& Palliative Medicine, 25(2), 81-87.

House, J. S. (2014). Americans’ Changing Lives: Waves I, II, III, IV, and V, 1986, 1989, 1994, 2002, and 2011. ICPSR04690-v7. Ann Arbor, MI: Inter-university Consortium for Political and Social Research [distributor]. http://doi.org/10.3886/ICPSR04690.v7

Infurna, F. J., Ram, N., \& Gerstorf, D. (2013). Level and change in perceived control predict 19year mortality: findings from the Americans' changing lives study. Developmental Psychology, 49(10), 1833-1847. doi:10.1037/a0031041 
Jackson, J., Knight, K., \& Rafferty, J. (2010). Race and unhealthy behaviors: Chronic stress, the HPA axis, and physical and mental health disparities over the life course. American Journal of Public Health, 100(5), 933-939.

Kämpfen, F., \& Maurer, J. (2016). Time to burn (calories)? The impact of retirement on physical activity among mature Americans. Journal of Health Economics, 45, 91-102.

Kaplan, M. S., Newsom, J. T., McFarland, B. H., \& Lu, L. (2001). Demographic and psychosocial correlates of physical activity in late life. Journal of Preventive Medicine, 21, 306-12.

Li, C., Lee, J., Chang, L., Liu, C., Chan, Y., Wen, C., ... Wen, C. P. (2016). Physical activity to overcome adversity of widowhood: Benefits beyond physical health. Medicine, 95(32), 4413.

Musick, M. A., \& Wilson, J. (2003). Volunteering and depression: the role of psychological and social resources in different age groups. Social Science \& Medicine, 56(2), 259-269.

Ng, D., \& Jeffery, R. (2003). Relationships between perceived stress and health behaviors in a sample of working adults. Health Psychology, 22(6), 638-642.

Office of Disease Prevention and Health Promotion, (2017). Healthy people 2020: Physical activity. Retrieved from https://www.healthypeople.gov/2020/topicsobjectives/topic/physical-activity

Pearlin, L., \& Skaff, M. (1996). Stress and the life course: A paradigmatic alliance. The Gerontologist, 36(2), 239-247.

Rosenfield, S., \& Mouzon, D. (2013). Gender and Mental Health. In C. S. Aneshensel, J. C. Phelan, \& A. Bierman (Eds.), Handbook of the Sociology of Mental Health (pp. 277-296). New York, NY: Springer Netherlands. 
Salmon, P. (2001). Effects of physical exercise on anxiety, depression, and sensitivity to stress: A unifying theory. Clinical Psychology Review, 21, 33-61.

Shaw, B. A., Liang, J., Krause, N., Gallant, M., \& McGeever, K. (2010). Age differences and social stratification in the long-term trajectories of leisure-time physical activity.The Journals of Gerontology, Series B, Psychological Sciences and Social Sciences, 65(6), 756766. doi:10.1093/geronb/gbq073

Stahl, S., \& Schulz, R. (2014). The effect of widowhood on husbands' and wives’ physical activity: The cardiovascular health study. The Journal of Behavioral Medicine, 37(4), 806-817.

Stetson, B., Rahn, J., Dubbert, P., Wilner, B., \& Mercury M. (1997). Prospective evaluation of the effects of stress on exercise adherence in community-residing women. Health Psychology, 16(6), 515-520.

Stults-Kolehmainen, M. A., \& Sinha, R. (2013). The effects of stress on physical activity and exercise. Sports Medicine, 44(1), 81-121.

Umberson, D., Liu, H. \& Reczek, C. (2008). Stress and Health Behaviour over the Life Course. In Turner \& Schieman Advances in Life Course Research, vol 13 (pp. 19-44). Oxford, UK: Elsevier.

U.S. Department of Health and Human Services, (2008). 2008 Physical activity guidelines for Americans. Retrieved from https://health.gov/paguidelines/guidelines/

Yang, Y., \& Lee, L. C. (2009). Sex and Race Disparities in Health: Cohort Variations in Life Course Patterns. Social Forces, 87(4), 2093-2124. 
Table 1. Participant Characteristics

\begin{tabular}{|c|c|c|c|}
\hline Characteristic & $\begin{array}{l}\text { Overall } \\
\text { N (\%) }\end{array}$ & $\begin{array}{c}\text { Men } \\
\text { N (\%) }\end{array}$ & $\begin{array}{c}\text { Women } \\
\text { N (\%) }\end{array}$ \\
\hline \multicolumn{4}{|l|}{ Gender } \\
\hline Male & $1357(38)$ & 1357 (100) & --- \\
\hline Female & $2259(62)$ & --- & $2259(100)$ \\
\hline \multicolumn{4}{|l|}{$\operatorname{Race}^{\mathrm{a} * * *}$} \\
\hline White & $2338(65)$ & 912 (67) & $1426(63)$ \\
\hline Black & $1174(33)$ & 397 (39) & 777 (44) \\
\hline American Indian & $138(4)$ & $57(4)$ & $81(4)$ \\
\hline Asian & $33(1)$ & $11(1)$ & $22(1)$ \\
\hline Hispanic & $40(1)$ & $17(1)$ & $23(1)$ \\
\hline Other & $10(0)$ & $6(0)$ & $4(0)$ \\
\hline \multicolumn{4}{|l|}{ Income $* * *$} \\
\hline$<25,000$ & $2350(65)$ & $746(55)$ & $1604(71)$ \\
\hline$\geq 25,000$ & $1266(35)$ & $611(45)$ & 655 (29) \\
\hline \multicolumn{4}{|l|}{ Education** } \\
\hline$<13$ years & $2387(66)$ & $828(61)$ & $1581(70)$ \\
\hline$\geq 13$ years & $1229(34)$ & 529 (39) & $678(30)$ \\
\hline \multicolumn{4}{|l|}{ Relationship Status*** } \\
\hline Married & $1976(55)$ & $885(65)$ & $1091(48)$ \\
\hline Widowed & $653(18)$ & $103(8)$ & $550(24)$ \\
\hline Divorced/separated & $582(16)$ & $182(13)$ & $400(18)$ \\
\hline
\end{tabular}




\begin{tabular}{|c|c|c|c|}
\hline Never married & $405(11)$ & $187(14)$ & $218(10)$ \\
\hline \multicolumn{4}{|l|}{ Functional Health Index*** } \\
\hline Most impaired & $189(5)$ & $56(4)$ & $133(6)$ \\
\hline Moderate impaired & $302(8)$ & $76(6)$ & $226(10)$ \\
\hline Least impaired & $348(10)$ & $94(7)$ & $254(11)$ \\
\hline Not impaired & 2777 (77) & $1131(83)$ & $1646(73)$ \\
\hline \multicolumn{4}{|l|}{ Life Events Experienced } \\
\hline Married** & $205(6)$ & $97(7)$ & $108(5)$ \\
\hline Divorced & $240(7)$ & $94(7)$ & $146(6)$ \\
\hline Widowed $* * *$ & 391 (11) & $94(7)$ & 297 (13) \\
\hline Friend died & $2368(65)$ & $873(64)$ & $1495(66)$ \\
\hline Child died $* * *$ & $210(6)$ & $53(4)$ & $157(7)$ \\
\hline Parent died & 849( 23) & $341(25)$ & $508(22)$ \\
\hline Became caregiver & $1657(46)$ & $607(45)$ & $1050(46)$ \\
\hline Retired & $1283(35)$ & $489(36)$ & $794(35)$ \\
\hline Lost job*** & $497(14)$ & $220(16)$ & $277(12)$ \\
\hline \multirow[t]{2}{*}{ Moved residence } & $1638(45)$ & $637(47)$ & $1001(44)$ \\
\hline & Mean \pm SD & Mean \pm SD & Mean \pm SD \\
\hline $\operatorname{Age}^{* * *}$ & $54.0 \pm 17.62$ & $52.0 \pm 17.42$ & $55.0 \pm 17.60$ \\
\hline $\mathrm{BMI}$ & $26.0 \pm 5.10$ & $26.0 \pm 4.23$ & $26.1 \pm 5.55$ \\
\hline Number of chronic conditions $* * *$ & $1.40 \pm 1.42$ & $1.12 \pm 1.33$ & $1.57 \pm 1.44$ \\
\hline Physical Activity Wave $1^{\mathrm{b} * * *}$ & $0.044 \pm 0.237$ & $0.073 \pm 0.229$ & $0.026 \pm 0.239$ \\
\hline Physical Activity Wave $2^{\mathrm{b} * * *}$ & $0.019 \pm 0.223$ & $0.051 \pm 0.216$ & $0.002 \pm 0.225$ \\
\hline
\end{tabular}




\begin{tabular}{|c|c|c|c|}
\hline Physical Activity Wave $3^{\mathrm{b} * * *}$ & $0.081 \pm 0.222$ & $0.11 \pm 0.211$ & $0.064 \pm 0.226$ \\
\hline Physical Activity Wave $4^{\mathrm{b} * * *}$ & $0.062 \pm 0.235$ & $0.099 \pm 0.224$ & $0.039 \pm 0.238$ \\
\hline Physical Activity Wave $5^{\mathrm{b} * * *}$ & $0.091 \pm 0.291$ & $0.123 \pm 0.203$ & $0.071 \pm 0.226$ \\
\hline \multicolumn{4}{|c|}{$\begin{array}{l}\text { Statistical significant difference between men and women }{ }^{* * *} p<0.001,{ }^{* *} p<0.01,{ }^{*} p<0.05 \\
+p<0.10\end{array}$} \\
\hline \multicolumn{4}{|c|}{$\begin{array}{l}\text { a Percentages added up to more than } 100 \% \text { because more than one response is possible. In the } \\
\text { analyses, race was coded as white }=1 \text {, nonwhite }=0 \text {. }\end{array}$} \\
\hline \multicolumn{4}{|c|}{$\begin{array}{l}{ }^{\mathrm{b}} \text { Three questions (frequency of exercise, walks, and gardening) were included in the physical } \\
\text { activity measure. Possible responses were often, sometimes, rarely, and never. An ordered } \\
\text { categorical confirmatory factor analysis model was fit to estimate a latent variable for physical } \\
\text { activity using wave } 1 \text { data. This model was used to give factor scores to all waves. Physical } \\
\text { activity ranges from }-0.45 \text { to } 0.41 \text {. }\end{array}$} \\
\hline
\end{tabular}


Table 2. Estimates from age-based growth models of major life events predicting physical activity $(\mathrm{N}=3,617)$

\begin{tabular}{|c|c|c|c|c|c|}
\hline $\begin{array}{l}\text { Key Independent } \\
\text { Variables }\end{array}$ & Full sample & Men & Women & Non-White & White \\
\hline \multicolumn{6}{|c|}{ For Intercept (baseline) } \\
\hline Married & -0.0141 & 0.0216 & -0.0348 & 0.0213 & -0.0023 \\
\hline Divorced & 0.0314 & 0.0219 & 0.0395 & 0.0015 & $0.0451+$ \\
\hline Widowed & -0.0059 & -0.0285 & -0.0026 & -0.0176 & -0.0049 \\
\hline Child died & 0.0005 & 0.0064 & -0.0017 & $0.0476 *$ & -0.0225 \\
\hline Parent died & $0.0132^{+}$ & 0.0069 & $0.0185^{*}$ & -0.0038 & 0.0105 \\
\hline Friend died & 0.0044 & 0.0077 & 0.0028 & $-0.0147+$ & $0.0093+$ \\
\hline Became caregiver & $0.0100^{+}$ & $0.0204 *$ & 0.0028 & 0.0161 & $0.0111+$ \\
\hline Moved & 0.0032 & -0.0026 & 0.0065 & 0.0154 & -0.0021 \\
\hline Lost job & 0.0183 & 0.0200 & 0.0174 & -0.0315 & $0.0260+$ \\
\hline Retired & $0.0306 * * *$ & 0.0183 & $0.0444 * * *$ & -0.0078 & $0.0396 * * *$ \\
\hline
\end{tabular}

\section{For Growth Rate}

$\begin{array}{lccccc}\text { Married } & -0.0009 & -0.0003 & -0.0011 & 0.0011 & -0.0005 \\ \text { Divorced } & 0.0002 & 0.0006 & 0.0001 & 0.0022 & 0.0004 \\ \text { Widowed } & -0.0008 & -0.00016 & -0.0002 & 0.0008 & -0.0009 \\ \text { Child died } & -0.0008 & 0.0000 & -0.0010 & 0.0005 & -0.0016\end{array}$




$\begin{array}{lccccc}\text { Parent died } & 0.0010^{*} & 0.0006 & 0.0014^{*} & 0.0001 & 0.0010^{+} \\ \text {Friend died } & 0.0006^{*} & 0.0011^{*} & 0.0002 & 0.0006 & 0.0007^{*} \\ \text { Became caregiver } & 0.0000 & 0.0005 & -0.0003 & -0.0004 & -0.0002 \\ \text { Moved } & 0.0003 & -0.0005 & 0.0008^{*} & -0.0001 & 0.0003 \\ & & & & & \\ \text { Lost job } & -0.0003 & -0.0002 & -0.0007 & -0.0027^{*} & 0.0002 \\ \text { Retired } & -0.0018^{*} & -0.0011 & -0.0028^{* *} & 0.0011 & -0.0026^{* *} \\ \end{array}$

Note: Models control for race (white vs. non-white), highest level of education (13+ education years), annual household income $(>\$ 25,000)$, body mass index, number of chronic conditions, functional health and the proportion of waves of data collection respondents participated in.

$* * * p<0.001, * * p<0.01,{ }^{*} p<0.05,+p<0.10$ 